\title{
Role of androgens for urethral homeostasis
}

\author{
Matthias D. Hofer ${ }^{1}$, Allen F. Morey ${ }^{2}$ \\ ${ }^{1}$ Department of Urology, Northwestern University, Chicago, IL, USA; ${ }^{2}$ Department of Urology, UT Southwestern, Dallas, TX, USA \\ Contributions: (I) Conception and design: All authors; (II) Administrative support: None; (III) Provision of study materials or patients: None; (IV) \\ Collection and assembly of data: All authors; (V) Data analysis and interpretation: All authors; (VI) Manuscript writing: All authors; (VII) Final \\ approval of manuscript: All authors. \\ Correspondence to: Allen F. Morey, MD. Department of Urology, UT Southwestern, 5323 Harry Hines Blvd., Dallas, TX 75390-9110, USA. \\ Email: allen.morey@utsouthwestern.edu.
}

Background: We observed that patients with hypogonadism are at higher risk to experience artificial urinary sphincter cuff erosion. Sphincter erosions have been found to be associated with urethral atrophy or compromised urethras subsequent to events limiting its blood supply. We therefore analyzed possible mechanisms how a decrease in testosterone serum levels can result decreased urethral blood flow.

Methods: In a cohort of $>1,200$ urethroplasties, tissue specimens obtained during surgeries were analyzed for expression of androgen receptor (AR), AR-responsive TIE-2 associated with angiogenesis, and the endothelial cell marker CD31 for determination of vessel counts were analyzed immunohistochemically. A total of 11 patients were included in whom both tissue and serum testosterone levels within 2 years of the urethroplasty was available. Low serum testosterone level defined as $<280 \mathrm{ng} / \mathrm{dL}$. Image J software was used to analyze expression profiles.

Results: Mean serum testosterone level was significant lower in hypogonadal patients (179.4 ng/dL) compared to eugonadal patients $(375.0 \mathrm{ng} / \mathrm{dL}, \mathrm{P}=0.003)$. Urethral tissue of hypogonadal patients showed decreased AR expression [1.11\% high power field (HPF)] compared to eugonadal patients $(1.62 \%, \mathrm{P}=0.016)$, decreased TIE-2 expression (1.84\% HPF vs. 3.08\%, $\mathrm{P}=0.006)$, and also decreased vessel counts (44.47 vessels/HPF vs. 98.33, $\mathrm{P}=0.004)$. There was a direct correlation of $\mathrm{AR}$ and TIE-2 expression levels with serum testosterone levels (rho 0.685, $\mathrm{P}=0.029$, and rho $0.773, \mathrm{P}=0.005$, respectively). Of note, we did not detect a difference in age, prior radiation, coronary artery disease or hypertension among hypo- or eugonadal patient. However, higher body mass index was associated with low serum testosterone levels.

Conclusions: Hypogonadal status is associated with decreased expression of AR and TIE-2 and also reduced vessel count in urethral tissue. We believe that the resulting decreased urethral vascularity subsequent to a hypogonadal state may be an important risk factor for complications of urethral surgery.

Keywords: Low testosterone; urethra; urethral atrophy

Submitted Dec 12, 2017. Accepted for publication Feb 07, 2018.

doi: $10.21037 /$ tau.2018.02.05

View this article at: http://dx.doi.org/10.21037/tau.2018.02.05

\section{Introduction}

We recently identified that hypogonadism is strongly associated with artificial urinary sphincter cuff erosions $(1,2)$. Within 8 years of implantation, we have observed that nearly all $(90 \%)$ of incontinent men with low testosterone levels can expect to experience erosion of their artificial urinary sphincter. We hypothesized that impaired urethral viability occurs in response to decrease serum androgen levels.

The association of testosterone and tissue homeostasis has been reported $(3,4)$ as has the association of tissue atrophy in response low testosterone levels for example in skeletal muscle (5) or bones (6). Similarly, the impact of androgens on angiogenesis and blood vessel function has been well-described (7-9). Mediators of androgen-induced angiogenesis include cytokines and growth factors such as 
VEGF (10), angiopoietin 1 and its receptor TIE-2 $(11,12)$.

We sought to establish the specific influence of hypogonadism on urethral angiogenesis and vascularity of the urethra and corpus spongiosum. In this current report we describe a mechanistic model of this association obtained in human tissue samples and review the potential role of testosterone replacement therapy in the context of urethral surgery.

\section{Methods}

\section{Patient cohort}

In a cohort of $>1,200$ urethroplasties performed between 2007 and 2016, eleven patients were identified who had both a testosterone level within 2 years of the urethroplasty and urethral tissue samples available. IRB approval had been obtained from the Institutional Review Board of the University of Texas Southwestern (STU 102012-021). This study was exempt from informed consent as archival tissue was used. All patients had strictures of idiopathic etiology without trauma or malformation history. All urethroplasties were excision and primary anastomoses. Also, none of the patients had testosterone replacement therapy in the past. Original tissue blocks were recut and stained for hematoxylin-eosin slides and with immunohistochemistry. Low serum testosterone was defined as $<280 \mathrm{ng} / \mathrm{dL}$ according to the cut-off level of the normal range at the UT Southwestern clinical laboratory.

\section{Immunobistochemistry}

DAKO PTLink Pre-treatment module heat-mediated antigen retrieval was performed (DAKO, Carpinteria, CA, USA) and staining processed as follows: CD31 (DAKO, Carpinteria, CA, USA): retrieval at low $\mathrm{pH}$ for $20 \mathrm{~min}$, dilution of antibody1:200; AR (DAKO, Carpinteria, CA, USA): retrieval at high $\mathrm{pH}$ for 20 minutes, dilution 1:50; TIE-2 (Abcam, Cambridge, MA, England): retrieval at low $\mathrm{pH}$ for 40 minutes, dilution 1:25. Staining was performed in an autostainer (DAKO, Carpinteria, CA, USA).

\section{Image analysis}

Slide pictures were obtained at $200 \times$ magnification with the manufacturer's camera and software (Nikon, Japan) and images processed with Image J software $(\mathrm{NIH}$, Bethesda, MD, USA). AR and TIE-2 expression were counted as percent positively stained cells per high power field (HPF) to account for variation in cellularity. Vessel count was determined as number of stained vessels (CD31 staining) per HPF.

\section{Statistical analysis}

Chi-square, Student's $t$, Mann-Whitney U, and Spearman's rho correlation tests were performed for statistical analysis using SPSS 20 for MAC (IBM Corp., Armonk, NY, USA).

\section{Results}

We found no significant difference in age, history of radiation, smoking, or comorbidities between hypogonadal and eugonadal patients. There was a trend towards an association between hypogonadal state and diabetes [2 of 5 (40\%) hypogonadal vs. 0/6 eugonadal patients, $\mathrm{P}=0.087$ ] and coronary artery disease [2/5 (40\%) vs. $0 / 6, \mathrm{P}=0.087]$, but this was not statistically significant. Hypogonadal patients had a significantly higher mean body mass index (BMI), however (39.82 vs. 25.57, $\mathrm{P}=0.011$ ), and $\mathrm{BMI}$ was correlated to testosterone levels (rho $-0.873, \mathrm{P}<0.001$ ). No difference existed in stricture characteristics between both groups including length, location, or recurrence after repair.

We found a significantly decreased AR expression among hypogonadal patients compared to eugonadal patients as shown in Figure $1 A, B(1.11 \%$ HPF vs. $1.62 \%, \mathrm{P}=0.016)$. In addition, we found a significant correlation of $\mathrm{AR}$ expression with serum testosterone levels (rho 0.685, $\mathrm{P}=0.029$ ). Next, we analyzed a downstream target of AR, TIE-2, that has been found to mediate AR-induced angiogenesis $(11,12)$. We again found a significantly decreased expression in hypogonadal patients compared to eugonadal patients $(1.84 \%$ $\mathrm{HPF}$ vs. $3.08 \%, \mathrm{P}=0.006$, Figure $1 C, D)$. Similar to $\mathrm{AR}$, TIE-2 expression showed a significant correlation to serum testosterone level (rho 0.773, $\mathrm{P}=0.005$ ). Hypogonadal patients also had decrease number of vessels in the urethral tissue compared to eugonadal patients as shown in Figure 1E,F (44.47 vessels/HPF vs. 98.33, $\mathrm{P}=0.004)$. There was no significant correlation of vessel count and serum testosterone (rho $0.515, \mathrm{P}=0.128$ ).

\section{Discussion}

Urethral tissue from patients with hypogonadism demonstrates reduced expression of AR, its downstream target TIE-2 involved in AR-mediated angiogenesis, and 

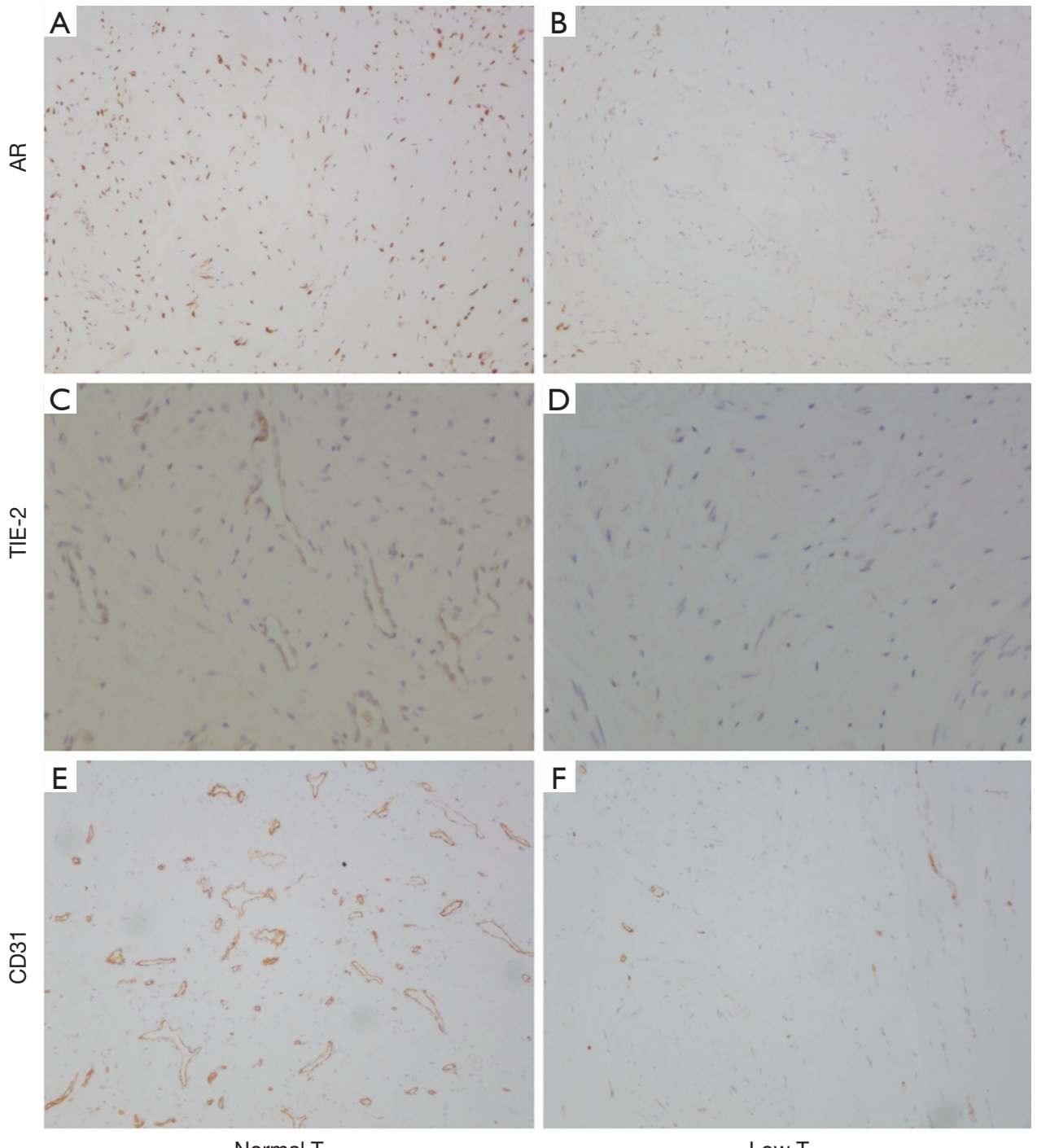

Figure 1 Expression of androgen receptor, TIE-2, and vessel count in urethral tissue. (A,B) Representative images of androgen receptor (AR) expression in patients with normal and with low serum testosterone levels. AR expression was expressed in many nuclei of cells of patients with normal testosterone levels whereas it was rather sparsely found in those with low testosterone levels; (C,D) TIE-2 expression was present scattered in patients with normal levels whereas it was only minimally expressed in patients with low testosterone levels; (E,F) the number of vessels per HPF was decreased in patients with low testosterone levels in contrast to patients with normal testosterone levels in which a fair amount of the vessels were present. (A,B) Anti-AR antibody, 100× magnification; (C,D) anti-TIE-2 antibody, 200× magnification; (E,F) anti-CD31 antibody, 40× magnification.

vascularity of urethral tissue. This suggests that androgens mediate urethral homeostasis by maintaining blood supply and viability. The implications of these findings suggest that elderly men with either idiopathic hypogonadism or androgen deprivation treatment for prostate cancer may be at increased risk for complications of urethral surgery.

Other reports confirm that compromise of urethral tissue with reduced physiologic viability confers susceptibility to AUS cuff erosion $(13,14)$. In these studies, factors that were believed or found to be a risk factor of AUS cuff erosion include prior AUS placement and prior urethral surgery as well as pelvic radiation $(13,14)$. All these factors have in common that they result in a decrease of blood flow to the urethra and corpus spongiosum for example due to surgical 
dissection or radiation-induced endarteritis. In our prior study a multivariable analysis including these factors and hypogonadism demonstrated that hypogonadism was the only independent risk factor for AUS erosion, however, suggesting its preeminent role for urethral tissue vascularity.

Androgen receptor (AR) expression is regulated in a tissue-specific manner. In skeletal muscle AR is upregulated in fibroblasts, endothelial and smooth muscle cells after testosterone stimulation (15), and testosterone deprivation may have a reverse effect. A decrease of AR expression in the bulbospongiosus muscle was observed in response to castration (16). These reports are congruent with our observation of decreased AR expression in the urethra and corpus spongiosum in hypogonadal patients. It should also be noted that we found a direct correlation of AR expression with serum testosterone levels. We also found a direct correlation of TIE-2 expression and serum testosterone levels as well as a significantly lower TIE-2 expression in hypogonadal patients. TIE-2 is a receptor for angiopoietin 1 and its expression is both regulated by AR and involved in AR-mediated angiogenesis (11). Including the fact that hypogonadal patients exhibited a significant decrease in vascularity in our tissue samples we believe that mechanistically low testosterone levels lead to decrease AR expression which results in decreased TIE-2 expression and androgen receptor-mediated angiogenesis in the urethra and corpus spongiosum. We believe that this could explain the pathophysiology for our finding that a hypogonadal state is associated with urethral atrophy and compromise.

The implications for reconstruction of urethral strictures are obvious. Although older men can be expected to have lower levels of circulating androgens, the paradigm for testosterone replacement prior to urethral reconstruction remains untested. We recently identified that older men have a higher risk of recurrence after urethroplasty and this may be related to decreased testosterone levels and resulting decreased angiogenesis with subsequently decreased degenerative potential (17). It should be noted that Levy et al. have reported equal success in younger and older patients undergoing urethroplasty, however, although in this study patients were only dichotomized as younger or older than 60 years (18) and not analyzed as a continuum of decades as in our study. An often utilized approach in pediatric urology is administration of preoperative testosterone to prepubertal boys with hypospadias to improve tissue vascularization and healing after hypospadias repair (18). We have found that adult hypogonadal men with AUS cuff erosions appear to be eager to undergo testosterone replacement therapy prior to AUS replacement when offered this option. The role of testosterone replacement prior to initial AUS placement is unknown, even though we have recently observed that nearly half of all men undergoing AUS surgery have low serum testosterone levels. Future studies are needed to confirm the prevalence of hypogonadism in adult urethroplasty patients and to clarify the role of testosterone replacement in those at risk.

Our study has several limitations. In addition to TIE-2 as AR-regulated factor involved in vasculogenesis other factors likely involved in this process, for example VEGF, were not studied and we also did not study systemic effects of testosterone. The aim was, however, to develop a hypothesis of the mechanistic relationship between low testosterone levels and urethral susceptibility to AUS erosion. A comprehensive analysis of all potential mechanisms would have been beyond the scope of this study and likely several studies. In addition, cytokine levels such that of VEGF is very difficult to determine in archival tissues and a prospective cohort would be necessary.

\section{Conclusions}

Hypogonadal men demonstrate decreased androgenrelated angiogenesis in urethral and corpus spongiosum tissue. We believe that reduced blood flow subsequent to low testosterone levels decreases the viability of urethra and corpus spongiosum and results in urethral atrophy, a condition which may compromise the outcomes of urethral surgery.

\section{Acknowledgements}

None.

\section{Footnote}

Conflicts of Interest: The authors have no conflicts of interest to declare.

Ethical Statement: IRB approval had been obtained from the Institutional Review Board of the University of Texas Southwestern (STU 102012-021). This study was exempt from informed consent as archival tissue was used.

\section{References}

1. Hofer MD, Morey AF, Sheth K, et al. Low Serum 
Testosterone Level Predisposes to Artificial Urinary Sphincter Cuff Erosion. Urology 2016;97:245-9.

2. Sundaram V, Cordon BH, Hofer MD, et al. Is Risk of Artificial Urethral Sphincter Cuff Erosion Higher in Patients with Penile Prosthesis? J Sex Med 2016;13:1432-7.

3. Ding EL, Song Y, Malik VS, et al. Sex differences of endogenous sex hormones and risk of type 2 diabetes: a systematic review and meta-analysis. JAMA 2006;295:1288-99.

4. Kelly DM, Jones TH. Testosterone and obesity. Obes Rev 2015;16:581-606.

5. Renoud A, Ecochard R, Marchand F, et al. Predictive parameters of accelerated muscle loss in men-MINOS study. Am J Med 2014;127:554-61.

6. Morgentaler A. Controversies and Advances With Testosterone Therapy: A 40-Year Perspective. Urology 2016;89:27-32.

7. Sieveking DP, Chow RW, Ng MK. Androgens, angiogenesis and cardiovascular regeneration. Curr Opin Endocrinol Diabetes Obes 2010;17:277-83.

8. Sieveking DP, Lim P, Chow RW, et al. A sex-specific role for androgens in angiogenesis. J Exp Med 2010;207:345-52.

9. Yoshida S, Ikeda Y, Aihara K. Roles of the Androgen-Androgen Receptor System in Vascular Angiogenesis. J Atheroscler Thromb 2016;23:257-65.

10. Eisermann K, Broderick CJ, Bazarov A, et al. Androgen up-regulates vascular endothelial growth factor expression in prostate cancer cells via an Sp1 binding site. Mol Cancer
2013;12:7.

11. Johansson A, Rudolfsson SH, Wikström P, et al. Altered levels of angiopoietin 1 and tie 2 are associated with androgen-regulated vascular regression and growth in the ventral prostate in adult mice and rats. Endocrinology 2005;146:3463-70.

12. Wang GM, Kovalenko B, Huang Y, et al. Vascular endothelial growth factor and angiopoietin are required for prostate regeneration. Prostate 2007;67:485-99.

13. Hoy NY, Rourke KF. Artificial Urinary Sphincter Outcomes in the "Fragile Urethra". Urology 2015;86:618-24.

14. McGeady JB, McAninch JW, Truesdale MD, et al. Artificial urinary sphincter placement in compromised urethras and survival: a comparison of virgin, radiated and reoperative cases. J Urol 2014;192:1756-61.

15. Sinha-Hikim I, Taylor WE, Gonzalez-Cadavid NF, et al. Androgen receptor in human skeletal muscle and cultured muscle satellite cells: up-regulation by androgen treatment. J Clin Endocrinol Metab 2004;89:5245-55.

16. Antonio J, Wilson JD, George FW. Effects of castration and androgen treatment on androgen-receptor levels in rat skeletal muscles. J Appl Physiol (1985) 1999;87:2016-9.

17. Viers BR, Pagliara TJ, Rew CA, et al. Urethral Reconstruction in Aging Male Patients. Urology 2018;113:209-14.

18. Levy M, Gor RA, Vanni AJ, et al. The Impact of Age on Urethroplasty Success. Urology 2017;107:232-8.
Cite this article as: Hofer MD, Morey AF. Role of androgens for urethral homeostasis. Transl Androl Urol 2018;7(4):521-525. doi: $10.21037 /$ tau.2018.02.05 